Correction

\title{
Correction to: Mapping Stresses on the Tibial Plateau Cartilage in an Ovine Model Using In-Vivo Gait Kinematics
}

\author{
Paris Vakiel (10, ${ }^{1,2}$ Mehdi Shekarforoush,,${ }^{1,2}$ Christopher R. Dennison, ${ }^{3}$ \\ Michael Scott, ${ }^{4}$ Gregory Muench, ${ }^{4}$ David A. Hart, ${ }^{1,5,6}$ \\ and Nigel G. Shrive ${ }^{1,2}$
}

\begin{abstract}
${ }^{1}$ McCaig Institute for Bone \& Joint Health, Cumming School of Medicine, University of Calgary, Calgary, AB, Canada; ${ }^{2}$ McCaig Institute for Bone and Joint Health, 3330 Hospital Drive Northwest, Calgary, AB T2N 4N1, Canada; ${ }^{3}$ Biomedical Instrumentation Laboratory, Department of Mechanical Engineering, University of Alberta, Edmonton, AB, Canada; ${ }^{4}$ Faculty of Veterinary Medicine, University of Calgary, Calgary, AB, Canada; ${ }^{5}$ Department of Surgery, Foothills Hospital, University of Calgary, Calgary, AB, Canada; and ${ }^{6}$ Faculty of Kinesiology, University of Calgary, Calgary, AB, Canada
\end{abstract}

(Published online 4 February 2021)

\section{Correction to:}

Annals of Biomedical Engineering (2020)

https://doi.org/10.1007/s10439-020-02650-6

This erratum is to correct the caption for Figure 4 and has been edited to reflect the revised format of the graph presented in this figure.

The original article can be found online at https://doi.org/10. 1007/s10439-020-2650.

Address correspondence to Paris Vakiel, McCaig Institute for Bone and Joint Health, 3330 Hospital Drive Northwest, Calgary, AB T2N 4N1, Canada. Electronic mail: Pa.vakil@gmail.com 


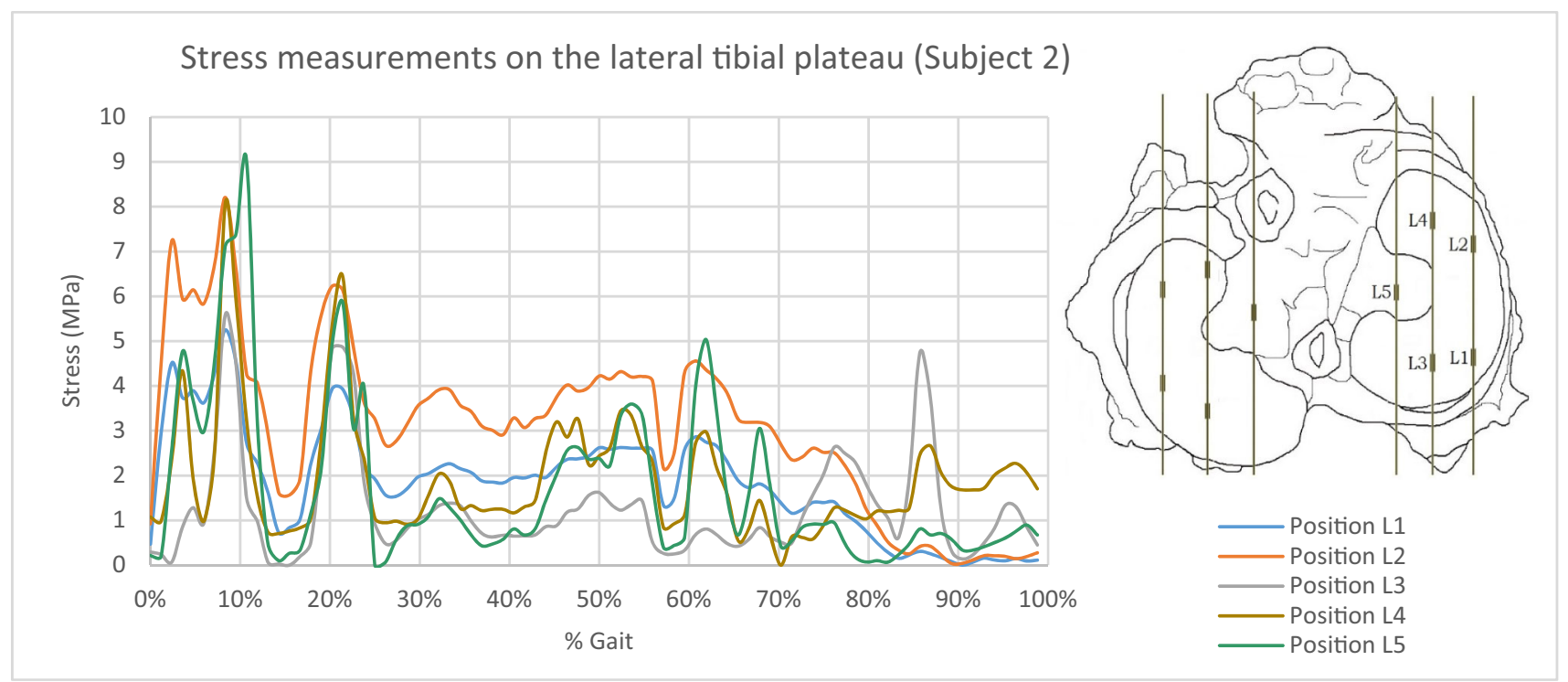

FIGURE 4. Stress Measurements for the full gait cycle of the median stride at five different positions on the lateral tibial plateau of Subject 2. All stress values are in MPa.

Publisher's Note Springer Nature remains neutral with regard to jurisdictional claims in published maps and institutional affiliations. 